FACTA UNIVERSITATIS

Series: Mechanical Engineering Vol. 18, N ${ }^{\circ}$ 2, 2020, pp. 255 - 267

https://doi.org/10.22190/FUME200601023A

Original scientific paper

\title{
EFFECT OF THE BIMODAL STRUCTURE PROCESSED BY ECAP AND SUBSEQUENT ROLLING ON STATIC STRENGTH AND SUPERPLASTICITY OF Al-Mg-Sc-Zr ALLOY
}

\author{
Elena Avtokratova, Oleg Sitdikov, Oksana Latypova, \\ Michael Markushev \\ Institute for Metals Superplasticity Problems RAS, Ufa, Russia
}

\begin{abstract}
Microstructure and mechanical properties of the $1570 \mathrm{C}$ aluminum alloy were studied after equal channel angular pressing (ECAP) to the strain of 3 at $325^{\circ} \mathrm{C}$ and subsequent warm and cold rolling with near $80 \%$ reductions at $325^{\circ} \mathrm{C}$ and $20^{\circ} \mathrm{C}$, respectively. Even containing a partially recrystallized bimodal structure with a volume fraction of ultrafine grains of 0.3 and their size not exceeding $2 \mu \mathrm{m}$, the alloy after ECAP demonstrated an excellent balance of room temperature static strength parameters (yield strength $(Y S) \approx 300 \mathrm{MPa}$, tensile strength $($ UTS $) \approx 400 \mathrm{MPa}$ and elongation $(E l) \approx 26 \%$ ), and high strain rate superplasticity (with maximum elongation exceeding $2500 \%$ at $520^{\circ} \mathrm{C}$ and a strain rate of $1.4 \times 10^{-2} \mathrm{~s}^{-1}$ ). Subsequent warm and cold rolling resulted in an increase in YS to 340 and $430 \mathrm{MPa}$ and UTS to 415 and $485 \mathrm{MPa}$ amid El decreased to 24 and $11 \%$, respectively. Despite the difference in the deformation structures formed in both rolling states, similar superplastic behavior was observed with maximum elongations of up to $3000 \%$ at temperatures of $500-520^{\circ} \mathrm{C}$ and strain rates of about $10^{-2} \mathrm{~s}^{-1}$. It was concluded that the initial processing of the alloy to relatively low ECAP strains before warm/cold rolling, leading to bimodal structure with a low fraction of ultrafine grains, is sufficient to ensure a favorable combination of both service and technological properties of the sheets obtained.
\end{abstract}

Key Words: Aluminum Alloy, Equal Channel Angular Pressing, Rolling, Superplasticity

\section{INTRODUCTION}

It is known that the balance of technological and service properties of commercial alloys, involving superplastic and static strength characteristics, can be significantly enhanced by processing an ultrafine-grained (UFG) structure (grain size less than $1 \mu \mathrm{m}$ )

Received June 01, 2020 / Accepted July 16, 2020

Corresponding author: Elena Avtokratova

Institute for Metals Superplasticity Problems RAS, Ufa, 450001, Russia

E-mail: avtokratova@imsp.ru 
using methods of severe plastic deformation (SPD) [1,2]. In pilot productions they are usually implemented by several techniques, such as equal channel angular pressing (ECAP), multidirectional isothermal forging, etc (e.g., [1-3]). These techniques can also be used in the UFG sheet manufacture by combining with conventional processes, such as rolling. Regarding the superplastic properties, it is known that there are some challenges by employing the number of UFG commercial aluminum sheets in superplastic forming, because of low stability of their microstructure under static and dynamic (deformation) annealing. The strong enhancement of stability of UFG structure is frequently achieved by simultaneous additions of few transition metals, such as $\mathrm{Mn}, \mathrm{Cr}, \mathrm{Zr}$, Sc, etc., forming high densities of nanosized aluminides [4-6]. For instance, unique characteristics of highstrain rate superplasticity were reported for the $\mathrm{Al}-\mathrm{Mg}-\mathrm{Sc}(\mathrm{Zr})$ alloys [5,7] with the nearly uniform UFG structures processed by SPD with high strains. Meanwhile, it was shown $[8,9]$ that such structures became unstable upon annealing after subsequent cold rolling due to a high driving force for the grain boundary migration in the heavily workhardened structures. In this way, decrease in SPD strain, allowing the UFG structure be partially developed by dynamic recrystallization to meet superplasticity in the early stages of subsequent hot deformation, would be a very promising technical approach. At the same time, the effect of markedly lowered straining on high-strain rate superplasticity in the $\mathrm{Al}-\mathrm{Mg}-\mathrm{Sc}(\mathrm{Zr})$ alloys, is not so obvious. Meanwhile, the SPD processed UFG alloys were found to demonstrate not only excellent superplasticity [5, 7], but also a unique balance of strength and ductility at ambient temperature after subsequent warm and cold rolling [10]. Therewith, the significance of the SPD conditions is ambiguous owing to a number of structural factors that concurrently affect the alloy mechanical behavior. For instance, the strengthening effect due to grain refinement may be less than that from work- and/or dispersion hardening due to the rearrangement of the dislocation structures and/or particle coarsening. Thus, the aim of the present study was to evaluate the effect of the warm ECAP to relatively low strains and subsequent warm and cold rolling (WR and CR), imitating two main routes of UFG sheet processing, on the static strength and superplastic behavior of the Al-Mg-Sc-Zr alloy.

\section{MATERIAL AND METHODS}

The semi-direct cast ingot of the commercial aluminum alloy $1570 \mathrm{C}(\mathrm{Al}-5 \mathrm{Mg}$ $0.18 \mathrm{Mn}-0.2 \mathrm{Sc}-0.08 \mathrm{Zr}-0.002 \mathrm{Be}(\mathrm{wt} \%)$ ) was homogenized at $360^{\circ} \mathrm{C}$ for 6 hours, and machined into plates of $150 \times 150 \times 30 \mathrm{~mm}^{3}$. ECAP was performed by the route $\mathrm{B}_{\mathrm{cz}}\left(90^{\circ}\right.$ rotation around the normal axis to the plate plane between passes) at $325^{\circ} \mathrm{C}$ to a strain of about 3 using a die with a rectangular cross section and a channel inner angle of $90^{\circ}$. WR and CR were performed along the last pressing direction at $325^{\circ} \mathrm{C}$ and $20^{\circ} \mathrm{C}$ with total reductions $85 \%$ and $80 \%$ ( $e=1.9$ and 1.6 , respectively). The room-temperature hardness was measured by the Vickers method using the Metrotest ITB-1-M device. Thermal stability of the structure processed was determined by 1-hr annealing in the temperature range of $350-520^{\circ} \mathrm{C}$. Tensile tests at room and elevated (up to $520^{\circ} \mathrm{C}$ ) temperatures were performed with Instron 1185 testing machine using dog-bone shape specimens with a gauge part $3 \times 6 \times 1 \mathrm{~mm}^{3}$ cut along the last pressing/rolling direction. 
Optical metallography (OM), scanning and transmission electron microscopy (SEM and TEM) were used to analyze the alloy microstructure. OM was performed with a Nikon L-150 optical microscope on the samples after standard mechanical polishing and etching in a Keller's reagent. Samples for SEM and TEM were electropolished at $20 \mathrm{~V}$ in a $30 \% \mathrm{HNO}_{3}$ and $70 \% \mathrm{CH}_{3} \mathrm{OH}$ solution at $-28^{\circ} \mathrm{C}$ using a Tenupol-5 unit. The SEM, including electron backscatter diffraction (EBSD) analysis, was carried out using a TESCAN MIRA 3 LMH field emission electron microscope equipped with the Oxford Instruments HKL Channel-5 system. TEM was performed with a microscope JEOL2000EX. On EBSD maps, the low- $\left(2^{\circ} \leq \Theta<15^{\circ}\right)$ and high-angle $\left(\Theta \geq 15^{\circ}\right)$ boundaries (LABs and HABs) were marked with gray and black lines, respectively. The scanning area reached $200 \times 200 \mu \mathrm{m}^{2}$ at scanning step varied from 0.05 to $0.2 \mu \mathrm{m}$, depending on the structure analyzed. The structural angular parameters, including the average misorientation angle of the intergranular boundaries $\Theta_{\text {ave }}$ and the fraction of HABs $f_{\mathrm{HABs}}$, were derived from the EBSD data after a standard noise-reduction procedure [11]. (Sub)grain boundaries with $\Theta<2^{\circ}$ were not taken into account. The sizes of grains and subgrains were measured by the "equivalent diameter" technique (upon conversion of the measurements of the area of crystallites into "equiareal circle diameter"), realized in the EBSD software. More details on methods of analysis are reported elsewhere [7, 9].

\section{RESULTS AND DISCUSSIONS}

\subsection{Microstructural changes}

The starting alloy state was characterized by an equiaxed grain structure with an average grain size of about $25 \mu \mathrm{m}$ (Fig. 1a, b) and the predominantly high-angle grain boundary spectrum with $f_{\mathrm{HABs}}$ of about 0.9 and $\Theta_{\text {ave }}$ of about $40^{\circ}$. Inside the grains, uniformly-distributed nanosized $\mathrm{Al}_{3}(\mathrm{Sc}, \mathrm{Zr})$ precipitates with a diameter of about $15 \mathrm{~nm}$ and a number density of $10^{4} \mu^{-3}$ were observed (Fig. 1c). ECAP led to a partial grain refinement and formation of a heterogeneous bimodal structure with the (ultra)fine grains developed in the vicinity of original boundaries, called as the mantle regions (Fig. $2 \mathrm{a}, \mathrm{d}, \mathrm{g}, \mathrm{j})$. The size of new grains was varied from 1 to $2 \mu \mathrm{m}$, while their volume fraction was as low as 0.3. Consequently, the majority of the material volume was still represented by almost equiaxed fragments of original grains of $15-20 \mu \mathrm{m}$ in diameter, containing subgrains of about $1 \mu \mathrm{m}$ in size, bounded by LABs. (Sub)grain boundary spectrum in this structure was characterized by two peaks in the low- and high-angle diapasons with the fraction of LABs of about 0.6 and the $\Theta_{\text {ave }}$ of only $18^{\circ}$. Thus, the structure processed was predominantly (ultra)fine polygonised and the size of (ultra)fine grains developed in the mantle regions was roughly the same as that of subgrains. It can be, therefore imagined that the new grains were formed via an increase in the misorientation of strain-induced LABs, which progressively transformed into HABs without a notable growth of new grains. Such a feature of the structure developed could be conditioned by continuous dynamic recrystallization [12], which can first occur near original grain boundaries during hightemperature ECAP of the investigated alloy $[9,13]$. 


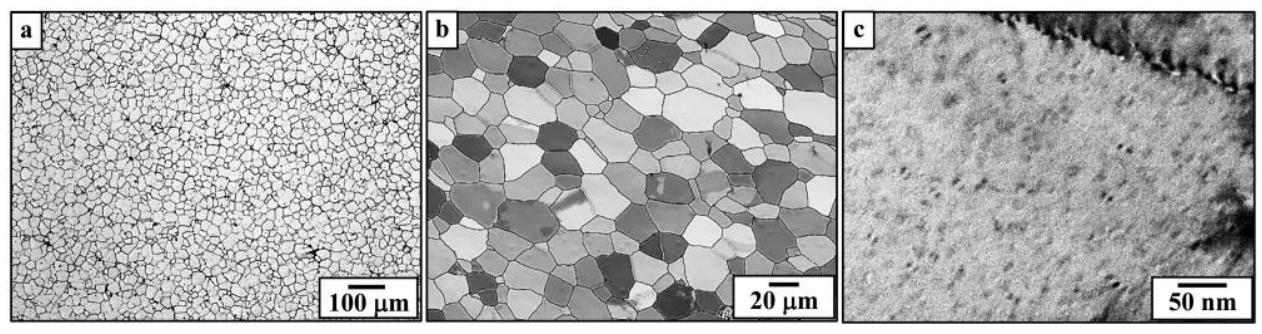

Fig. 1 OM (a); SEM (b) and TEM (c) structure of the homogenized alloy
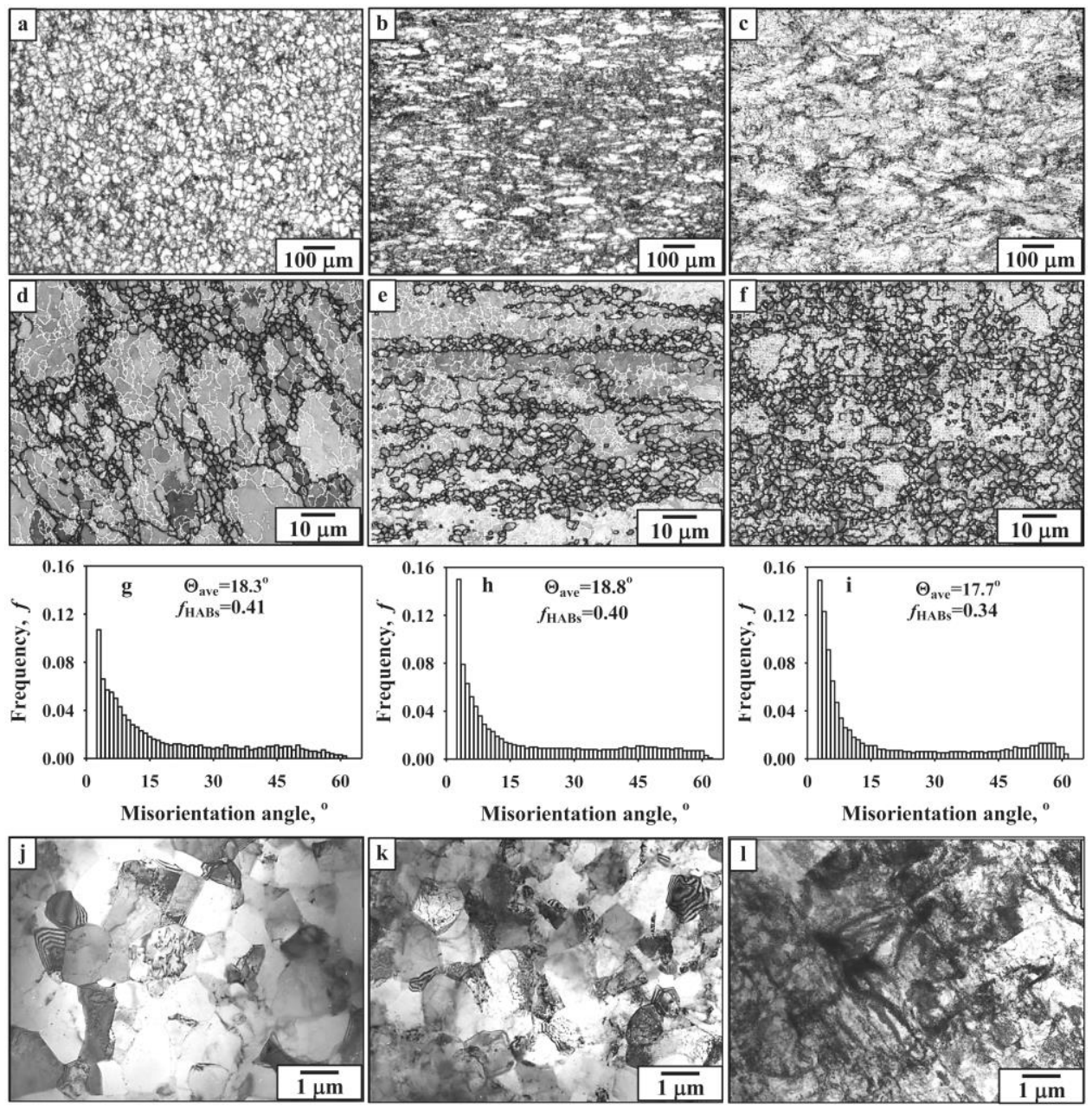

Fig. 2 OM (a-c), SEM-EBSD (d-i) and TEM (j-1) structures and corresponding (sub)grain boundary spectrums of in the alloy after $\operatorname{ECAP}(\mathrm{a}, \mathrm{d}, \mathrm{g}, \mathrm{j})$; ECAP and subsequent WR (b,e,h,k); and CR (c,f,i,l): pressing/rolling direction is horizontal 
WR subsequent to ECAP resulted mainly in pancaking and flattening of coarse remnant original grains in accordance to the macroscopic straining of a billet (Fig. 2b). Therewith, it might be expected that the alloy structure could exhibit at least more homogeneous distribution of fine grains owing to continuation of recrystallization [14]. However, their fraction in the mantle regions only slightly increased to $0.35-0.40$, whereas the shape and sizes of both fine grains and subgrains were scarcely changed (Fig. 2b, e, h, k). Also the angular parameters of the structure remained close to those after ECAP (Fig. 2g, h). This may imply that the straining occurred mainly in the mantle regions by grain boundary sliding (GBS), which was attributed to the ultrafine grain size and a relatively high deformation temperature, resulting in dissipation and almost complete relaxation of the deformation energy introduced by rolling [12, 14]. Meanwhile, the microstructural development in the coarse grains can be ascribed to the formation of a dynamically equilibrium substructure stabilized by coherent aluminides of Sc and $\mathrm{Zr}$ (Fig. 1c) that effectively suppressed dynamic recrystallization $[15,16]$. Besides, an additional assumption was that ECAP realized a simple shear deformation mode, being particularly important for grain refinement at high temperatures, while the pure shear implemented in a conventional process, such as WR, could not complete recrystallization under the considered deformation conditions [17].

$\mathrm{CR}$, in turn, resulted in the formation of a heavily-deformed structure with a lower crystallite size (about $0.3 \mu \mathrm{m}$ ) and an increased (up to 0.7) fraction of LABs (Fig. 2c,f,i,l). TEM analysis (Fig. 2l) revealed also high-density dislocation structures arranged in cells and deformation bands. Note also that the deformation microstructures evolved were apparently non-uniform on the mesoscopic level, as the necklace-like structure processed by ECAP (Fig. 2a,d) led to more heterogeneous and dense dislocation structures near the mantle regions of fine grains, where the grain boundaries served actively as sources and/or barriers for lattice dislocations. In contrast, the coarse remnant grains containing LABs transformed into less developed and more uniform deformation structures, stabilized by the $\mathrm{Al}_{3}(\mathrm{Sc}, \mathrm{Zr})$ precipitates.

\subsection{Room-temperature mechanical properties}

The room-temperature hardness and tensile strength parameters of the alloy before and after ECAP and subsequent rolling are represented in Table 1. Besides, the appropriate data for the alloy with almost fully recrystallized structure with the grain size of about $1 \mu \mathrm{m}$ processed by ECAP at $325^{\circ} \mathrm{C}$ to $e=10$ and subsequent WR and CR [18], are also shown for comparison.

Evaluation of the mechanical properties showed that the processed alloy demonstrated a favorable balance of high strength at reasonably high ductility. Namely, in comparison to the initial alloy state, hardness (Hv), the yield and ultimate tensile strength (YS and UTS) were noticeably increased after processing, especially after CR (in about 1.4, 1.8 and 1.4 times, respectively). Such an alloy strengthening is quite typical of work-hardening materials $[6,19]$ and mainly caused by grain refinement and development of the dislocation/ (sub)grain structures described above. Meanwhile, no alloy ductility decrease due to ECAP and further WR was found. To the contrary, the alloy ductility significantly decreased after CR, even although its level, however, still remained quite high exceeding $10 \%$. 
Table 1 Room temperature mechanical properties of the alloy

\begin{tabular}{lccccc}
\hline Condition & $\begin{array}{c}\mathrm{H} \\
\mathrm{v}\end{array}$ & $\begin{array}{c}\text { YS, } \\
\text { MPa }\end{array}$ & $\begin{array}{c}\text { UTS, } \\
\text { MPa }\end{array}$ & $\begin{array}{c}\text { YS/UT } \\
\text { El, \% }\end{array}$ & \\
\hline Initial & 105 & 240 & 355 & 0.67 & 28 \\
ECAP $(e=3)$ & 110 & 295 & 390 & 0.76 & 26 \\
ECAP $(e=3)+$ WR & 120 & 340 & 415 & 0.81 & 24 \\
ECAP $(e=3)+$ CR & 145 & 430 & 485 & 0.89 & 13 \\
ECAP $(e=10)[18]$ & - & 310 & 390 & 0.80 & 31 \\
ECAP $(e=10)+$ WR $[18]$ & - & 295 & 400 & 0.74 & 25 \\
ECAP $(e=10)+$ CR $[18]$ & - & 520 & 550 & 0.94 & 13 \\
\hline
\end{tabular}

It is well known that the main feature of the work-hardened material is a low elongation to failure (uniform elongation) because of a faster increase in YS than UTS, resulted in restricted capacity of further strain-hardening [20]. So even warm straining resulted in the sense increase of the ratio YS/UTS from about 0.7 to about 0.8 , the main reason of which was the formation of quite equilibrium partially recrystallized structure with ultrafine grains and subgrains. A further decreased gap between YS and UTS in the CR processed alloy (to YS/UTS $\approx 0.9$ ) signaled the lower strain hardening capability of the structure and, hence, lower stability of the plastic flow in the material, as its lower uniform elongations, compared to the other conditions investigated. On the other hand, as also mentioned above, the structures, developed in coarse grain interiors under WR and CR, were apparently near homogeneous on the mesoscopic level. In the both cases this homogeneity was attributed to a uniform distribution of the $\mathrm{Al}_{3}(\mathrm{Sc}, \mathrm{Zr})$ precipitates in the matrix (Fig. 1c). The latter are known to effectively interact with the lattice dislocations and homogenize the dislocation slip during straining $[15,16,21]$, thereby promoting relatively high uniform elongations. This may increase to some extent the alloy ductility even in the highly deformed condition.

Table 1 also shows that despite more intense grain refinement with increasing ECAP strain to $e=10$ [18], neither processing the present alloy by ECAP nor subsequent WR improved significantly both static strength and ductility at ambient temperature. This suggests that the grain boundary (Hall-Petch) strengthening [19], which should occur upon grain refinement via the transformation of the subgrain structure into an ultrafine recrystallized one, was almost completely compensated by the simultaneous softening caused by consumption of the dislocation/sub-grain structure. Also concurrent alloy ductility increase up to $30 \%$ was conditioned by the formation of a more homogeneous fine grain structure after ECAP. However, this advantage disappeared after the subsequent WR, when the alloy ductility fell to $25 \%$. In contrast, CR after ECAP to $e=10$ resulted in more significant alloy strengthening than CR after ECAP to $e=3$ with extremely high YS and UTS values for non-age hardenable alloys, amid nearly the same total elongation. Such a balance resulted from superposition of several factors, including both grain boundary- and dislocation strengthening. Namely, ECAP provided remarkable grain refinement, while the subsequent CR introduced, in turn, highly deformed substructures with increased dislocation density into the UFG structure. 


\subsection{Annealing behavior}

It was found that under post-deformation annealing, the structures developed by ECAP and subsequent both warm and cold rolling (Fig. 2) were replaced with statically recrystallized/recovered ones. Regardless the annealing temperature, the structures in all the alloy states remained bimodal and consisted of larger grains, containing substructure, that were surrounded by areas with smaller grains (Fig. 3).

As seen in Fig. 3a, b, d, e, g, h and Table 2, under annealing, performed after warm straining, a normal grain growth took place in areas of fine grains, while coarse grains remained fairly stable. According to Table 2, the grain size in the mantle regions almost did
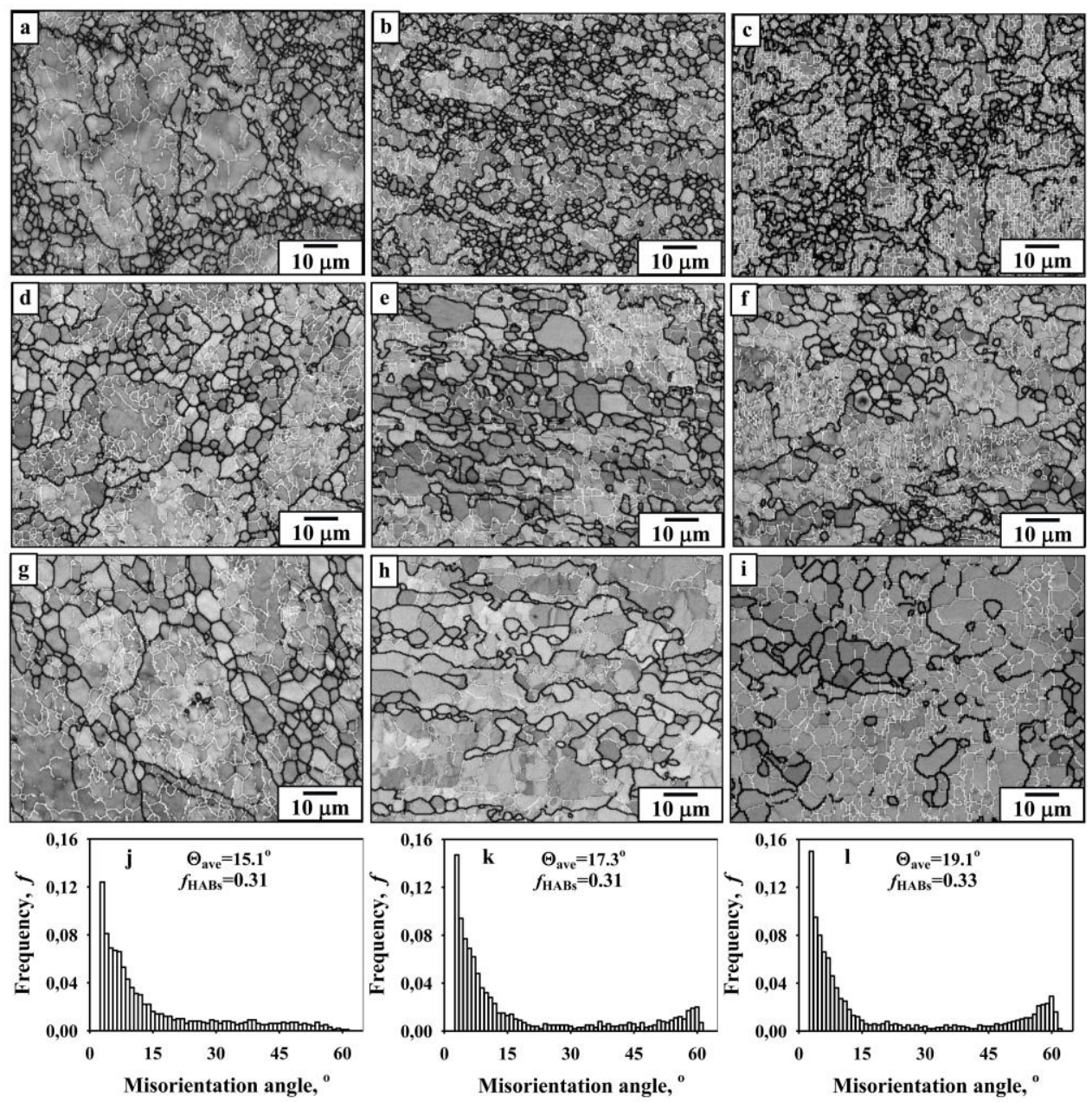

Fig. 3 Structures and (sub)grain boundary misorientations developed after 1-hr annealing at $425^{\circ} \mathrm{C}(\mathrm{a}, \mathrm{b}, \mathrm{c}), 475^{\circ} \mathrm{C}(\mathrm{d}, \mathrm{e}, \mathrm{f}, \mathrm{j}, \mathrm{k}, \mathrm{l})$ and $520^{\circ} \mathrm{C}(\mathrm{g}, \mathrm{h}, \mathrm{i})$ in the alloy after ECAP $(\mathrm{a}, \mathrm{d}, \mathrm{g}, \mathrm{j})$, ECAP and WR (b,e,h,k), ECAP and CR (c,f,i,l). Pressing/rolling axis is horizontal 
Table 2 Effect of annealing temperature on the grain size in the mantle regions

\begin{tabular}{lccccc}
\hline Condition & as-processed & \multicolumn{4}{c}{ Annealing temperature } \\
\cline { 3 - 6 } & & $425^{\circ} \mathrm{C}$ & $450^{\circ} \mathrm{C}$ & $475^{\circ} \mathrm{C}$ & $520^{\circ} \mathrm{C}$ \\
\hline ECAP & 1.4 & 2.0 & 2.1 & 2.8 & 4.2 \\
ECAP + WR & 1.3 & 1.6 & 1.9 & 2.5 & 3.5 \\
ECAP + CR & - & 2.2 & 2.4 & 2.5 & 3.9 \\
\hline
\end{tabular}

not change during annealing to $425-450^{\circ} \mathrm{C}$ and increased at higher temperatures (for example, twice - after annealing at $475^{\circ} \mathrm{C} \mathrm{C}$ and about threefold - at $520^{\circ} \mathrm{C}$ ). However, even after annealing at $520^{\circ} \mathrm{C}$, the absolute grain size in the mantle did not exceed $4.5 \mu \mathrm{m}$. Besides, the LABs formed after ECAP and subsequent WR were preserved in the interiors of coarse grains and were not ubiquitously converted to HABs (Fig. 3). Therewith, angular structural parameters $\left(f_{\mathrm{HABs}}\right.$ and $\left.\Theta_{\mathrm{ave}}\right)$ somewhat decreased at high annealing temperatures, probably mostly due to a decrease in the total length of HABs upon grain coarsening [12]. It is safe to assume that the microstructural stability observed in both recrystallized and nonrecrystallized regions is mainly conditioned by the uniform spatial distribution of dispersed $\mathrm{Al}_{3}(\mathrm{Sc}, \mathrm{Zr})$ phases. The latter, as known, effectively pin grain boundaries, as well as individual dislocations and dislocation structures, thereby prohibiting their rearrangement and, consequently, preventing grain growth and occurrence of static recrystallization $[4,5]$.

In the cold-rolled alloy, in contrast, structural changes in the mantle regions, where the original fine-grain structure possessed a much higher dislocation density (Fig. 2), were caused mainly by static recrystallization followed by normal grain growth (Fig. 3c,f,i). As the most possible way, static recrystallization occurred there in a continuous manner due to the presence of a large number of pre-existing (ultra)fine grains produced by ECAP, which were then severely strained during rolling. According to [22], some of them containing a lower dislocation density served as potential nuclei for static recrystallization and could further recover and grow during annealing to consume neighboring fine grains with a higher dislocation density. At the same time, more homogeneous and less dislocation-profuse areas containing LABs, which were formed in grain cores, still underwent static recovery and were characterized by the development of a polygonized structure stabilized by nanosized precipitates. Unlike the mantle regions, only static recovery was operated there as the main restoration mechanism during annealing. Thus, the development of the new fine grains around the coarse remnant ones gave back a necklace-like grain structure in the SPD processed and annealed material [9].

It is also interesting to note that both the (sub)grain boundary spectrum and the average parameters of the structure that developed during annealing of the alloy subjected to ECAP and CR were close to those obtained at the corresponding annealing temperatures after ECAP, as well as after WR (Fig. 3 and Table 2). Thus, despite the different operating structural mechanisms, quite similar structures were formed during annealing in the alloy processed to different treatment routes. This may indicate that there would be no significant difference in the microstructures that developed in these alloy states upon its heating and soaking prior to straining at elevated temperatures, involving superplastic forming. 


\subsection{Superplastic properties}

Tensile tests, carried out in a wide temperature range from 350 to $520^{\circ} \mathrm{C}$ (Fig. 4), showed that even with such a low volume fraction of ultrafine grains as 0.3 , the alloy after ECAP displayed both high strain rate- and low temperature superplasticity [2] with strain rate sensitivity coefficients, $m>0.35$ (Fig. 4 a,b). Maximum elongations, up to $2600 \%$ and $400 \%$, were observed at a strain rate of $10^{-2} \mathrm{~s}^{-1}$ at $520^{\circ} \mathrm{C}$ and $350^{\circ} \mathrm{C}$, respectively. After the subsequent WR, the alloy demonstrated even better superplastic behavior with elongations up to $3000 \%$ at $500^{\circ} \mathrm{C}$ and a strain rate of $5.6 \times 10^{-2} \mathrm{~s}^{-1}$ (Fig. $4 \mathrm{c}, \mathrm{d}$ ).
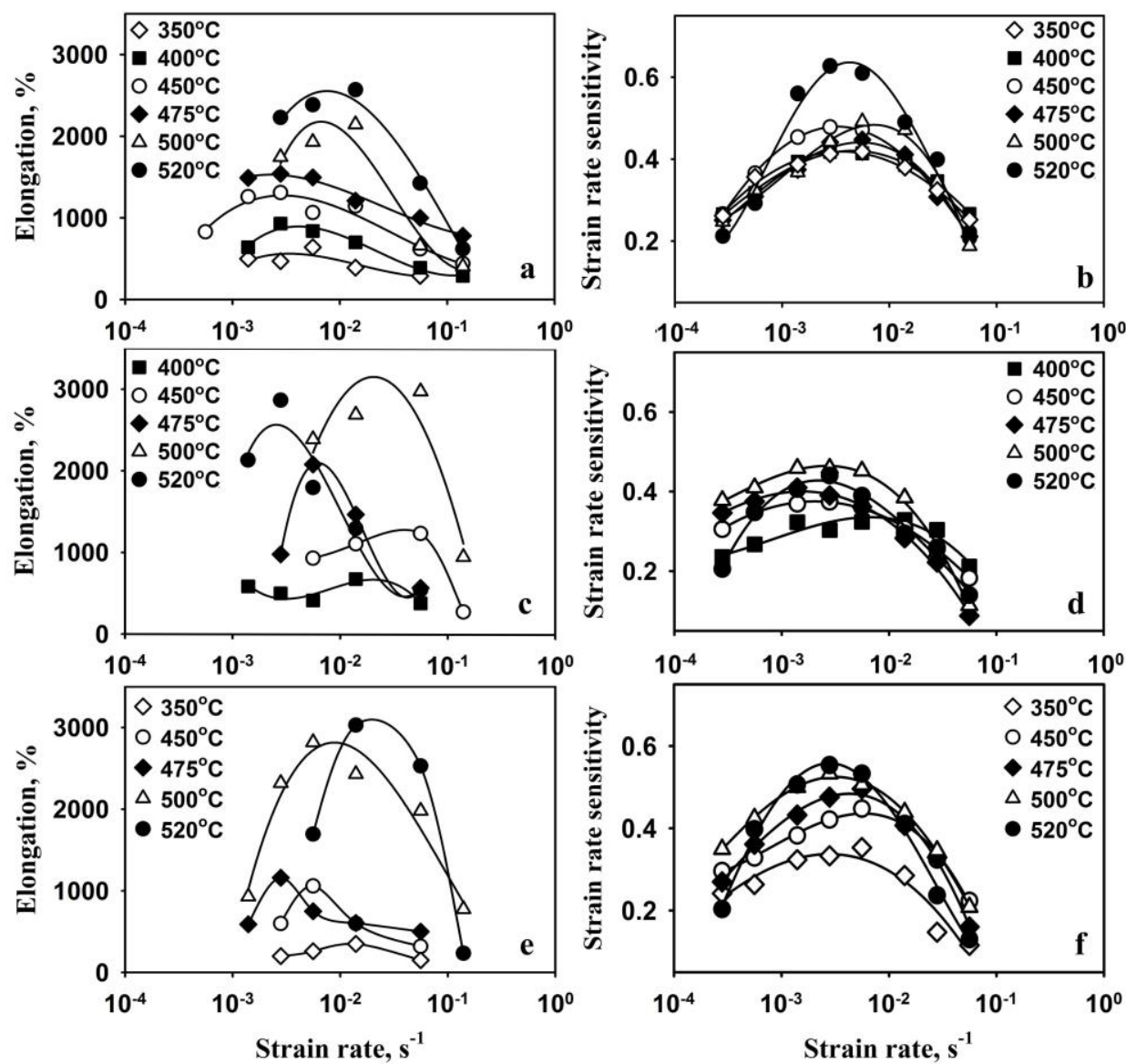

Fig. 4 Superplastic characteristics of the alloy at various temperatures and strain rates in the states after ECAP $(\mathrm{a}, \mathrm{b})$; ECAP and WR $(\mathrm{c}, \mathrm{d})$; ECAP and CR $(\mathrm{e}, \mathrm{f})$

After CR the superplastic characteristics were also extremely high: at a strain rate of $10^{-2} \mathrm{~s}^{-1}$, the elongation reached $3030 \%$ at $520^{\circ} \mathrm{C}$ and $350 \%$ at $350^{\circ} \mathrm{C}$ with a maximum $\mathrm{m}$ varying from 0.3 to 0.5 (Fig. 4e,f). Such unique properties can be discussed as follows. As can be imagined from the previous section, 1-hr heating/soaking of the material at the 
testing temperatures investigated, led to the development of quite similar bimodal structures with relatively stable sub-grain regions and about $30 \%$ of (ultra)fine grains underwent the normal grain growth (Fig. 3). Despite the above changes, the fine grains in such structures, as well as the subgrains, still remained fairly dispersed just before testing, even at the highest temperature of $520^{\circ} \mathrm{C}$, which signaled their high thermal stability.

Structural analysis in the gage section of samples after maximum elongations (Fig. 5) showed in turn that superplastic deformation led to the transformation of the bimodal structures into fully recrystallized ones with an average grain size of about $8.5 \mu \mathrm{m}$ in the warm deformed states and $10.5 \mu \mathrm{m}$ after CR. In addition, the evolved grain structures were characterized by similar (sub)grain boundary spectrums and mean values of angular parameters. Thus, new grain structures were mainly developed in all alloy states via recrystallization, occurring in the early stages of tensile deformation [23]. The new grains maintained an almost equiaxed shape (Fig. 5 a, d, g) even at high elongations (up to $3000 \%$ ), which explicitly referred to a large contribution of GBS to the total deformation. This conclusion was also supported by the deformation relief formed on the surfaces of the tensile samples, where all the signs of GBS were clearly evident (Fig. 5c, f, i). The data
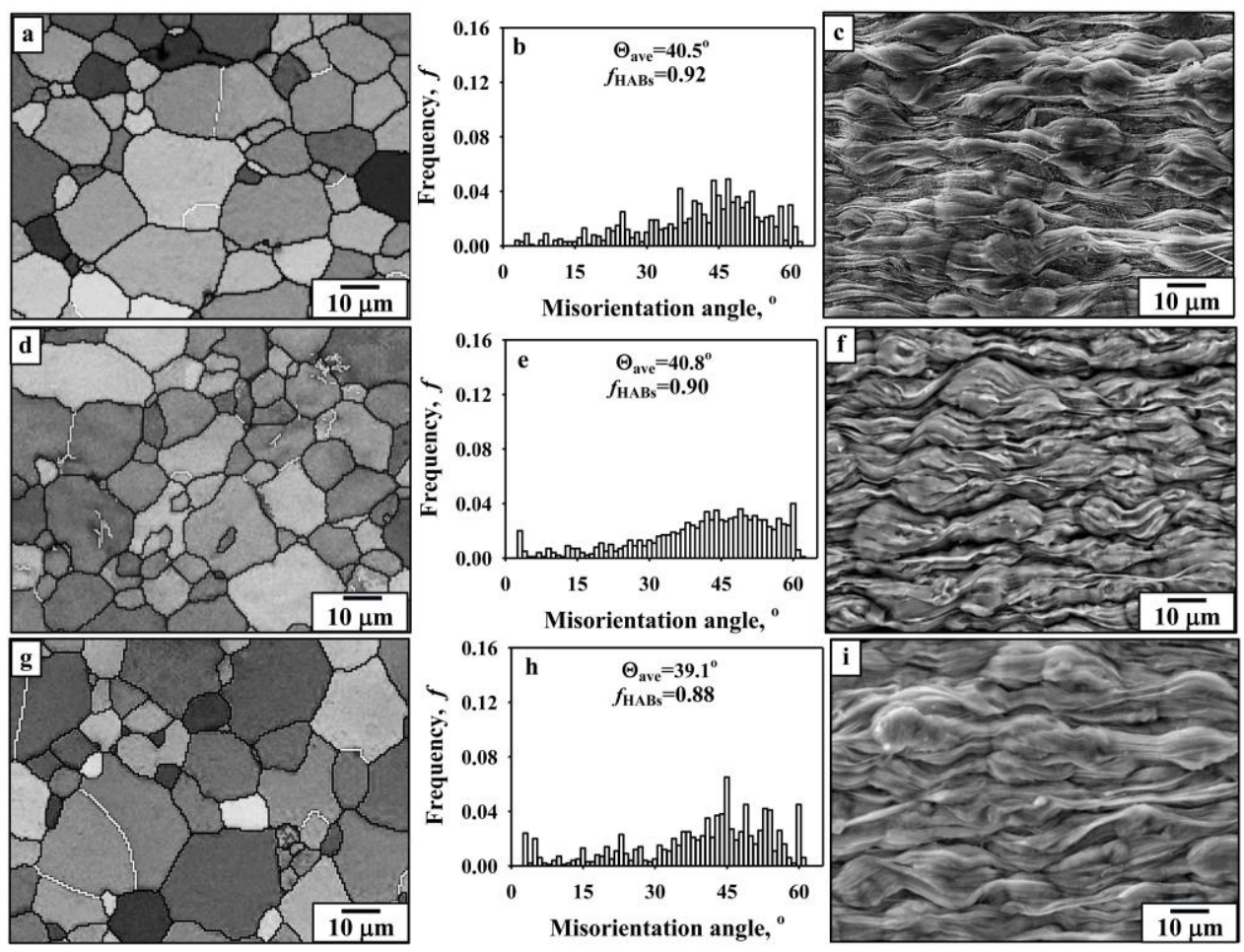

Fig. 5 Structures, (sub)grain boundary misorientations and deformation relief developed upon tension at $1.410^{-2} \mathrm{~s}^{-1}$ to maximum elongations in the specimens after ECAP at $520^{\circ} \mathrm{C}(\mathrm{a}-\mathrm{c})$; ECAP and $\mathrm{WR}$ at $500^{\circ} \mathrm{C}(\mathrm{d}-\mathrm{f})$; ECAP and $\mathrm{CR}$ at $520^{\circ} \mathrm{C}(\mathrm{g}-\mathrm{i})$ : (a,b,d,e,g,h) SEM-EBSD; (c,f,i) SEM. Tensile axis is horizontal 
obtained also allow concluding that complex additions of $\mathrm{Sc}$ and $\mathrm{Zr}$ to the aluminum alloy were quite effective for stabilizing the grain structure, ensuring extensive operation of GBS following dynamic recrystallization. The strong pinning effect of $\mathrm{Al}_{3}(\mathrm{Sc}, \mathrm{Zr})$ dispersoids limited the grain growth at elevated temperatures and prevented the degradation of superplastic characteristics. This allowed a sustained behavior of the alloy, contributing to extremely high elongations to failure.

\section{CONCLUSIONS}

The structure and mechanical properties of the commercial $1570 \mathrm{C}$ (Al-5Mg-0.18Mn$0.2 \mathrm{Sc}-0.08 \mathrm{Zr}-0.01 \mathrm{Fe}-0.01 \mathrm{Si}$, wt.\%) alloy were studied upon combination of ECAP of a homogenized ingot with the strain of $e=3$ at $325^{\circ} \mathrm{C}$ and subsequent warm and cold rolling with the total reduction of $85 \%(e=1.9)$ at $325^{\circ} \mathrm{C}$ and $80 \%(e=1.6)$ at $20^{\circ} \mathrm{C}$, respectively. The main results can be summarized as follows:

1. Under warm ECAP conditions, the alloy grain refinement occurred with the formation of a bimodal structure, which was a mantle of new (ultra)fine grains not exceeding $2 \mu \mathrm{m}$ in size with a volume fraction of about 0.3 around fragments of coarse original grains containing subgrains. Subsequent WR did not significantly change the type and parameters of as-ECAPed structure. During CR after ECAP, high-intense dislocation structures developed in regions of fine grains, while more uniform cell-type structures were obtained within the remnant original grains.

2. Analysis of the alloy room temperature tensile behavior showed that due to the formation of the above structures, the alloy in all processed states after ECAP with $e=3$ exhibited a favorable balance of moderate-to-high strength and a reasonably high ductility. Such a balance did not change much with further grain refinement upon increasing the ECAP strain to $e=10$ before WR. However, the mechanical properties obtained in the cold rolled alloy subsequent to ECAP with $e=3$ conceded to those after $\mathrm{e}=10$, when much higher static strength was achieved amid roughly the same ductility.

3. One-hour annealing of the alloy in the temperature range up to $520^{\circ} \mathrm{C}$ after ECAP, as further WR, led to minor normal grain growth in the fine-grain mantle regions, along with maintaining a stable subgrain structure in the cores of the remnant original grains. On the contrary, when annealing a cold-rolled alloy, intense and uniform dislocation structures in the mantle and core regions, respectively, were transformed into arrays of fine statically recrystallized grains and statically recovered subgrains. Therewith, despite the operation of different structural mechanisms, quite similar structures were formed in all three states of the alloy after annealing.

4. The formation of bimodal/partially recrystallized (ultra)fine-grained structures with a predominant fraction of LABs by ECAP and subsequent cold/warm rolling was sufficient to achieve high strain rate superplasticity in the $1570 \mathrm{C}$ aluminum alloy with elongations exceeding $2500 \%$. Therewith, the (ultra)fine-grain structure mainly developed via dynamic recrystallization occurring at the early stages of superplastic flow, and remained stable due to the stabilizing effect of nanoscale $\mathrm{Al}_{3}(\mathrm{Sc}, \mathrm{Zr})$ dispersoids present in the alloy. 
Acknowledgements: The work was supported by the Ministry of Science and Higher Education of Russian Federation under the state assignment of IMSP RAS no. AAAA-A19-119021390107-8. Some graphs and micrographs in Figs. 2, 4 and 5 were reproduced from Avtokratova, E., Latypova, O., Sitdikov, O., Markushev, M., 2019, Superplastic behavior of the Al-Mg-Sc-Zr alloy with bimodal structure processed by equal channel angular pressing and subsequent rolling, AIP Conference Proceedings, 2167, 020022.

\section{REFERENCES}

1. Valiev, R.Z, Islamgaliev, R.K, Alexandrov, I.V., 2000, Bulk nanostructured materials from severe plastic deformation, Progress in Materials Science, 45, pp. 103-189.

2. Mulyukov, R.R., Imayev, R.M., Nazarov, A.A., Imayev, M.F., Imayev, V.M., 2014, Superplasticity of Ultrafine Grained Alloys: Experiment, Theory, Technologies, Moscow: Nauka, 284 p. (in Russian).

3. Markushev M.V., 2011, On the eeffectiveness of some methods of severe plastic deformation for bulk nanostructured materials processing, Letters on Materials, 1, pp. 36-42.

4. Riddle, Y.W., Sanders, T.H., 2004, A study of coarsening, recrystallization, and morphology of microstructure in Al-Sc-(Zr)-(Mg) alloys, Metallurgical and Materials Transactions A, 35, pp. 341-350.

5. Liu, F.C., Ma, Z.Y., Achieving exceptionally high superplasticity at high strain rates in a micrograined Al-Mg-Sc alloy produced by friction stir processing, 2008, Scripta Materialia, 59, pp. 882-885.

6. Markushev, M.V., Avtokratova, E.V., Sitdikov, O.Sh., 2017, Effect of the initial state on nanostructuring and strengthening of middle- and high-strength age-hardenable aluminum alloys under severe plastic deformation (Review), Letters on materials, 7(4), pp. 459-464.

7. Avtokratova, E., Sitdikov, O., Markushev, M., Mulyukov, R., 2012, Extraordinary high-strain rate superplasticity of severely deformed Al-Mg-Sc-Zr alloy, Materials Science and Engineering A, 538, pp. 386-390.

8. Sitdikov, O., Avtokratova, E., Babicheva, R., Sakai, Tsuzaki, K., Watanabe, Y., 2012, Influence of processing regimes on fine-grained microstructure development in an Al-Mg-Sc alloy by hot equal-channel angular pressing, Materials Transactions, 53, pp. 56-62.

9. Avtokratova, E., Sitdikov, O., Mukhametdinova, O., Markushev, M., Murty, S.V.S.N., Prasad, M.J.N.V., Kashyap, B.P., 2016, Microstructural evolution in Al-Mg-Sc-Zr alloy during severe plastic deformation and annealing, Journal of Alloys and Compounds, 673, pp. 182-194.

10. Sitdikov, O.Sh., Avtokratova, E.V., Ilyasov, R.R., Markushev, M.V., 2020, Structure and Mechanical Properties of the Aluminum Alloy 1570C after Multidirectional Forging with Decreasing Temperature and Subsequent Rolling, Journal of Physics: Conference Series, 1431 012053, doi:10.1088/1742-6596/1431/1/012053.

11. Channel 5: User Manual, Oxford Instruments HKL, 2007, https://caf.ua.edu/wpcontent/uploads/docs/JEOL-7000FOxford_Channel_5_User_Manual.pdf

12. Humphreys, F.J., Hartherly, M., 2004, Recrystallization and related annealing phenomena, 2nd edn., Elsevier Ltd., $605 \mathrm{p}$.

13. Sitdikov, O., Avtokratova, E., Sakai, T., 2015, Microstructural and texture changes during equal channel angular pressing of an Al-Mg-Sc alloy, Journal of Alloys and Compounds, 648, pp. 195-204.

14. Sitdikov, O., Avtokratova, E., Latypova, O., Markushev, M., 2018, Structure and superplasticity of the Al-Mg-TM alloy after equal channel angular pressing and rolling, Letters on Materials, 8(4s), pp.: 561-566.

15. Apps, P.J., Berta, M., Prangnell, P.B., 2005, The effect of dispersoids on the grain refinement mechanisms during deformation of aluminium alloys to ultrahigh strains, Acta Materialia, 53, pp. 499-511.

16. Huang, K., Marthinsen, K., Zhao, Q., Logé, R.E., 2018, The double-edge effect of second-phase particles on the recrystallization behaviour and associated mechanical properties of metallic materials, Progress in Materials Science, 92, pp. 284-359.

17. Driver, J., 2018, The limitations of continuous dynamic recrystallization (CDRX) of aluminium alloys, Materials Letters, 222, pp. 135-137.

18. Avtokratova, E.V., Markushev, M.V., Sitdikov O.Sh., Method of production of sheet semiproduct from aluminummagnesium alloy, RF Patent 0002575264 C1 (20.02.2016).

19. Russell, A.M., Lee, K.L., 2005, Structure-property relations in nonferrous metals, Hoboken, Wiley, 520 p.

20. Zheng, R., Bhattacharjee, T., Shibata, A., Tsuji, N., Ma, Ch., 2016, Effect of accumulative roll bonding (ARB) and subsequent aging on microstructure and mechanical properties of 2024 Al alloy, Materials Transactions, 57, pp. 1462-1470. 
21. Markushev, M.V., Avtokratova, E.V., Krymskiy S.V., Sitdikov, O.Sh., 2018, Effect of precipitates on nanostructuring and strengthening of high-strength aluminum alloys under high pressure torsion, Journal of Alloys and Compounds, 743, pp. 773-779.

22. Belyakov, A., Sakai, T., Miura, H., Kaibyshev, R., Tsuzaki, K., 2002, Continuous recrystallization in austenitic stainless steel after large strain deformation, Acta Materialia, 50, pp. 1547-1557.

23. Yang, X., Miura H., Sakai T., 2002, Continuous dynamic recrystallization in a superplastic 7075 aluminum alloy, Materials Transactions, 43, pp. 2400-2407. 